\title{
Combinational risk factors of metabolic syndrome identified by fuzzy neural network analysis of health-check data
}

Yasunori Ushida ${ }^{1}$, Ryuji Kato ${ }^{1}$, Kosuke Niwa², Daisuke Tanimura ${ }^{3}$, Hideo lzawa ${ }^{3}$, Kenji Yasui ${ }^{4,5}$, Tomokazu Takase ${ }^{2}$, Yasuko Yoshida ${ }^{2,6}$, Mitsuo Kawase ${ }^{2}$, Tsutomu Yoshida ${ }^{7}$, Toyoaki Murohara ${ }^{3}$ and Hiroyuki Honda ${ }^{1,6^{*}}$

\begin{abstract}
Background: Lifestyle-related diseases represented by metabolic syndrome develop as results of complex interaction. By using health check-up data from two large studies collected during a long-term follow-up, we searched for risk factors associated with the development of metabolic syndrome.

Methods: In our original study, we selected 77 case subjects who developed metabolic syndrome during the follow-up and 152 healthy control subjects who were free of lifestyle-related risk components from among 1803 Japanese male employees. In a replication study, we selected 2196 case subjects and 2196 healthy control subjects from among 31343 other Japanese male employees. By means of a bioinformatics approach using a fuzzy neural network (FNN), we searched any significant combinations that are associated with MetS. To ensure that the risk combination selected by FNN analysis was statistically reliable, we performed logistic regression analysis including adjustment.
\end{abstract}

Results: We selected a combination of an elevated level of $\gamma$-glutamyltranspeptidase ( $\gamma$-GTP) and an elevated white blood cell (WBC) count as the most significant combination of risk factors for the development of metabolic syndrome. The FNN also identified the same tendency in a replication study. The clinical characteristics of $\gamma$-GTP level and WBC count were statistically significant even after adjustment, confirming that the results obtained from the fuzzy neural network are reasonable. Correlation ratio showed that an elevated level of $\mathrm{Y}$-GTP is associated with habitual drinking of alcohol and a high WBC count is associated with habitual smoking.

Conclusions: This result obtained by fuzzy neural network analysis of health check-up data from large long-term studies can be useful in providing a personalized novel diagnostic and therapeutic method involving the $\gamma$-GTP level and the WBC count.

Keywords: Data mining, Combinational risk factor, Fuzzy neural network, Glutamyltranspeptidase, Lifestyle disease, Personalized diagnostic method, White blood cell

\section{Background}

Metabolic syndrome (MetS) is characterized by a clustering of metabolic abnormalities, including glucose intolerance, insulin resistance, central obesity, dyslipidemia, and hypertension, and it has been identified as a frequent cause to the development of cardiovascular disease [1].

\footnotetext{
* Correspondence: honda@nubio.nagoya-u.ac.jp

${ }^{1}$ School of Engineering, Nagoya University, Furo-cho, Chikusa-ku, Nagoya 464-8603, Japan

${ }^{6}$ MEXT Innovative Research Center for Preventative Medical Engineering, Furo-cho, Chikusa-ku, Nagoya 464-8601, Japan

Full list of author information is available at the end of the article
}

The prevalence of MetS in Japan has increased over recent decades as a result of changes in diet and physical activity [2]. To investigate the relationship between diet or physical activity and risk marker plays effective roles in finding the most suitable lifestyle factor to improve developing MetS. It is useful for proposing a personalized diagnostic and therapeutic method. There is also an urgent need to establish an appropriate and sensitive screening marker to identify individuals at a high risk of developing MetS, thereby preventing a further increase in its incidence. So far, indices such as the low-density 
lipoprotein (LDL) to high-density lipoprotein (HDL) ratio $(\mathrm{L} / \mathrm{H})[3]$ or the ratio of adiponectin to homeostasis model assessment-insulin resistance (adiponectin/HOMA-IR ratio) [4] have been proposed as combinational risk factors. We have also reported that a combination of adiponectin receptor 1 (ADIPOR1; rs1539355) with an environmental factor (smoking habit) is suitable as a combinational risk factor for MetS [5]. There is, however, a need to identify new combinational risk factors.

In this study, we used a fuzzy neural network (FNN) in a bioinformatics approach to search for complex risk characteristics. Hirose et al. predicted the prevalence of MetS using artificial neural network [6]. The FNN is one of artificial neural network models that have been used in medical research as a powerful tool for the accurate detection of causal relationships [7-10]. FNN analysis has two main advantages. The first is its ability to select parameters on the basis of a parameterincrease method to permit the identification of the most influential parameters in the data. FNN analysis has the same predictable ability as multiple logistic regression. The second is its ability to extract predictive rules called fuzzy rule that can predict objective properties to reproduce the results.

So far, FNN has shown considerable flexibility in modeling of such complex phenomena as biochemical engineering processes (modeling of links between process valuables and process outputs) [11,12], food science (modeling of links between chemical components and sensory evaluation) [13], protein structural science (modeling of links between amino acid sequences and enzyme function) [14], housing science (modeling of links between physical environmental factors and human sensory evaluations) [15], and peptide science (modeling of links between peptide sequences and peptide functions) $[16,17]$. We therefore conjectured that FNN might serve as a suitable method for identifying specific characteristics that affect the pathogenesis of MetS.

The present study had two chief merits. The first was that the studies were based on subjects receiving health check-ups rather than on clinical patients; this has the advantage that periodical health examination is free of model bias, so that our results apply to the general population. The second merit was the high quality of our data because the relevant studies involved large numbers of subjects who were followed over a long time (at least seven years).

Overall, the aim of our studies was to identify reliable combinational risk factors associated with MetS by using an FNN and to contribute to the prevention of MetS by mitigating the identified risk combination.

\section{Methods}

\section{Study design}

To identify a significant combination of factors associated with MetS, we performed a two-stage study. The clinical characteristics before study start are summarized in Tables 1 and 2 . In the original study, we selected 77 case subjects and 152 healthy control subjects from among 1803 Japanese male employees [5]. This longitudinal study was conducted by using health check-up data collected during a long-term follow-up (at least seven years). A replication study involved 2196 case subjects and 2196 healthy control subjects from among another 31343 other Japanese male employees. This study was also a longitudinal one and was conducted over eight years. All studies were performed according to the guidelines of the Declaration of

Table 1 Characteristics of original study

\begin{tabular}{|c|c|c|c|c|c|}
\hline Characteristic & $\mathbf{n}$ & Case mean $\pm S D$ or $n(\%)$ & $\mathbf{n}$ & Healthy control mean \pm SD or $n(\%)$ & $P$ value \\
\hline Male n (\%) & 77 & $77(100)$ & 152 & $152(100)$ & 1.000 \\
\hline Age (years) & 77 & $31.4 \pm 7.5$ & 152 & $30.6 \pm 4.6$ & 0.299 \\
\hline Height (cm) & 77 & $172.1 \pm 5.4$ & 152 & $170.9 \pm 5.5$ & 0.125 \\
\hline Weight (kg) & 77 & $68.2 \pm 5.8$ & 152 & $59.9 \pm 6.3$ & $8.28 \times 10^{-19}$ \\
\hline $\mathrm{BMI}\left(\mathrm{kg} / \mathrm{m}^{2}\right)$ & 77 & $23.0 \pm 1.4$ & 152 & $20.5 \pm 1.9$ & $1.58 \times 10^{-21}$ \\
\hline Systolic blood pressure $(\mathrm{mmHg})$ & 75 & $130.0 \pm 12.5$ & 152 & $116.9 \pm 11.2$ & $7.45 \times 10^{-14}$ \\
\hline Diastolic blood pressure (mmHg) & 75 & $78.4 \pm 9.2$ & 152 & $69.8 \pm 7.0$ & $1.92 \times 10^{-13}$ \\
\hline Serum total cholesterol (mg/dl) & 57 & $187.5 \pm 28.5$ & 99 & $166.0 \pm 21.5$ & $3.37 \times 10^{-7}$ \\
\hline Serum triglycerides (mg/dl) & 57 & $166.0 \pm 148.7$ & 98 & $74.1 \pm 34.9$ & $2.74 \times 10^{-8}$ \\
\hline Serum HDL-cholesterol (mg/dl) & 54 & $48.0 \pm 11.0$ & 90 & $57.1 \pm 9.8$ & $9.14 \times 10^{-7}$ \\
\hline Fasting plasma glucose (mg/dl) & 53 & $92.2 \pm 9.7$ & 85 & $88.2 \pm 7.9$ & $9.60 \times 10^{-3}$ \\
\hline Alcohol habit n (\%) & 76 & $63(82.9)$ & 152 & $131(86.2)$ & 0.513 \\
\hline Smoking habit n (\%) & 75 & $51(68.0)$ & 151 & $81(53.6)$ & $3.94 \times 10^{-2}$ \\
\hline
\end{tabular}

Data are mean \pm SD or $n(\%)$ unless noted otherwise.

Differences in characteristics between case and healthy control subjects were evaluated by linear regression analysis. 
Table 2 Characteristics of replication study

\begin{tabular}{|c|c|c|c|c|c|}
\hline Characteristic & $\mathrm{n}$ & Case mean \pm SD or $n(\%)$ & $\mathrm{n}$ & Healthy control mean \pm SD or $n(\%)$ & $P$ value \\
\hline Male n (\%) & 2196 & $2196(100)$ & 2196 & $2196(100)$ & 1.000 \\
\hline Age (years) & 2196 & $43.5 \pm 7.7$ & 2196 & $43.4 \pm 5.4$ & 0.519 \\
\hline Height $(\mathrm{cm})$ & 2196 & $170.3 \pm 5.7$ & 2196 & $169 \pm 5.8$ & $1.58 \times 10^{-13}$ \\
\hline Weight (kg) & 2196 & $72.4 \pm 9.1$ & 2196 & $60.4 \pm 6.7$ & $<1.0 \times 10^{-99}$ \\
\hline $\mathrm{BMI}\left(\mathrm{kg} / \mathrm{m}^{2}\right)$ & 2196 & $24.9 \pm 2.7$ & 2196 & $21.1 \pm 1.9$ & $<1.0 \times 10^{-99}$ \\
\hline Systolic blood pressure $(\mathrm{mmHg})$ & 2194 & $125 \pm 13.7$ & 2196 & $110.4 \pm 9.4$ & $<1.0 \times 10^{-99}$ \\
\hline Diastolic blood pressure $(\mathrm{mmHg})$ & 2195 & $79.9 \pm 10.0$ & 2196 & $69.3 \pm 7.6$ & $<1.0 \times 10^{-99}$ \\
\hline Serum total cholesterol (mg/dl) & 2196 & $204.9 \pm 34.8$ & 2196 & $186.7 \pm 30.4$ & $3.10 \times 10^{-73}$ \\
\hline Serum triglycerides (mg/dl) & 2196 & $161.4 \pm 115.6$ & 2196 & $76.1 \pm 28.0$ & $<1.0 \times 10^{-99}$ \\
\hline Serum HDL-cholesterol (mg/dl) & 2196 & $55.0 \pm 13.3$ & 2196 & $67.6 \pm 14.8$ & $<1.0 \times 10^{-99}$ \\
\hline Fasting plasma glucose (mg/dl) & 2196 & $99.7 \pm 19.9$ & 2196 & $90.1 \pm 7.4$ & $1.28 \times 10^{-95}$ \\
\hline Alcohol habit n (\%) & 2194 & $1693(77.2)$ & 2195 & $1704(77.6)$ & 0.712 \\
\hline Smoking habit n (\%) & 2195 & $1427(65.0)$ & 2195 & $1195(54.4)$ & $8.17 \times 10^{-13}$ \\
\hline
\end{tabular}

Data are mean \pm SD or $\mathrm{n}(\%)$ unless noted otherwise.

Differences in characteristics between case and healthy control subjects were evaluated by linear regression analysis.

Helsinki. Informed consent was obtained from all participants, and the studies were approved by Nagoya University School of Medicine. In both studies, we used clinical data before follow-up to predict the cause of MetS.

\section{Definitions of case, healthy control and normal control}

We used the criteria proposed by the Japan Society for the Study of Obesity (JASSO) [18] to identify subjects with MetS and supercontrol subjects.

1) Obesity: Waist circumference $\geq 85 \mathrm{~cm}$ in men or body-mass index (BMI) $\geq 25 \mathrm{~kg} / \mathrm{m}^{2}$ if the waist circumference was not measured.

2) Raised blood pressure: systolic blood pressure $\geq 130 \mathrm{mmHg}$ and/or diastolic blood pressure $\geq 85 \mathrm{mmHg}$.

3) Dyslipidemia: triglyceride $\geq 150 \mathrm{mg} / \mathrm{dL}$ and/or HDL cholesterol $<40 \mathrm{mg} / \mathrm{dL}$

4) Raised fasting glucose: fasting glucose $\geq 110 \mathrm{mg} / \mathrm{dL}$

Subjects were classified as suffering from MetS if they were obese and they showed any two of the other three criteria. Subjects who were free of any of the risk components were classified as supercontrol. Then we defined case, healthy control and normal control according to the criteria below.

Case: Subjects who developed MetS during the follow-up.

Healthy control: Subjects who were remained as supercontrol during the follow-up.

Normal control: Subjects who weren't MetS during follow-up.
Subjects with antihypertensive, lipid-lowering and anti-diabetic agents were excluded from analysis.

\section{Measurements}

The baseline health examination performed before follow-up included physical measurements, serum biochemical measurements, urine measurements, medication use and a questionnaire. Physical measurements of height, weight and body mass index were measured in the fasting state. Blood samples were obtained from subjects in the fasted condition for serum biochemical measurements. After the subject had rested for $10 \mathrm{~min}$ in sitting position, $14 \mathrm{ml}$ of blood were collected from the antecubital vein into tubes containing EDTA. After blood samples were sent to the clinical laboratory testing company, biochemical measurements were determined according to standard laboratory procedures. Biochemical measurements collected in this study include;

(1) Lipids: total cholesterol, triglyceride and HDLcholesterol.

(2) Carbohydrate: glucose.

(3) Non-protein nitrogenous compounds: urea nitrogen, creatinine and uric acid.

(4) Serum enzymes: $\gamma$-glutamyltranspeptidase $(\gamma-G T P)$, glutamic-oxyacetic transaminase (GOT), glutamicpyvuvic transaminase (GPT).

(5) Hematology: red blood cells (RBC), hemoglobin, hematocrit and white blood cells (WBC).

Urine samples were also collected in the morning. After urine samples were sent to clinical laboratory testing company, urine uribilinogen, urine protein, urine 
sugar and urinary occult blood were measured. Medication use was assessed by the examining physicians. Drinking habit and smoking habit were collected by standard questionnaire. The questionnaire asked about the frequency of alcohol consumption on a weekly basis and smoking habit (never, past or current smoker). Drinking habit was defined as the subject who drank once a week and more. Smoking habit was defined as past or current smoker. In replication study, exercise habit was also divided into four categories by the time of exercise per week; exercising every day, exercising twice or more a week, exercising once a week and no-exercising. The aim of our studies was to identify risk factors from routine health check-up parameters generally measured. Therefore, the well-defined risk factors such as insulin weren't measured in our study.

\section{FNN analysis}

We conducted an FNN analysis to identify any significant combinations that are associated with MetS. The procedure for constructing the model is shown schematically in Figure 1. This model has two inputs $x_{1}$ and $x_{2}$, one output $y^{*}$, and two membership functions $f_{\text {low }}$ and $f_{\text {high }}$ in each premise. FNN has three kinds of connection weights: $W_{\mathrm{c}}, W_{\mathrm{g}}$, and $W_{\mathrm{f}}$ [19]. The connection weights $W_{\mathrm{c}}$ and $W_{\mathrm{g}}$ determine the positions and gradients of the sigmoid functions; these decide the grade of each membership function $f_{\text {low }}$ or $f_{\text {high }}$ by means of the formula shown below,

$$
f(x)=1 /\left[1+\exp \left\{-W_{g}\left(x+W_{c}\right)\right\}\right]
$$

where $x$ is input value and $f(x)$ is the product of the grade of membership function. The products of the grades are fed to the next unit $\Pi$. $W_{\mathrm{f}}$ is the weight of each production rule and decides the output $y^{*}$ by means of the sum of the connection weights $W_{\mathrm{f}}$ and $\Pi$. In our original study, for input data we used 16 clinical characteristics that were not directly related to MetS criteria (Table 3). In our replication study, we used the two clinical characteristics that were identified as a result of the original study. All datasets were randomly arranged, divided equally into five datasets, and subjected to a fivefold cross-validation (CV) by using four datasets as training data and one dataset for validation. Through this fivefold $\mathrm{CV}$, the combination of two input parameters that provided the best predictive accuracy as an average throughout the $\mathrm{CV}$ was selected by means of the forward-selection method. The accuracy was calculated as shown below, and the model with the highest accuracy was selected as the best combination.

\section{$\operatorname{Accuracy}(\%)$}

$=\{($ the number of correct estimation for training data $)$ $/($ the number of training data $)\} \times 1 / 3$

$+\{$ (the number of correct estimation for test data) $/($ the number of test data $)\} \times 2 / 3$

Here, we judged that a correct estimation was achieved if the output signal $y^{*}$ from the model was more than 0 for a case subject and less than 0 for a healthy control subject; otherwise, the estimation was judged to be incorrect. We compared the accuracy in FNN analysis with those in multiple linear regression and multiple logistic regression.

\section{Statistical analysis}

To ensure that the risk combination selected by FNN analysis was statistically reliable, we performed logistic regression analysis involving a selected characteristic as

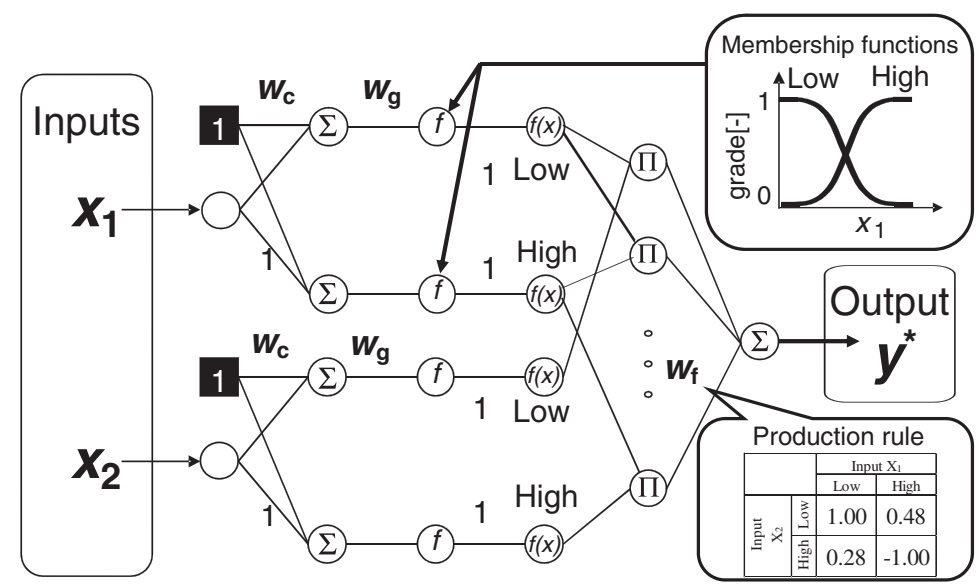

Figure 1 Fuzzy neural network (FNN) model (two inputs, one output). The most effective combination of input characteristic contributing to MetS was identified by the use of parameter-increasing method. 
Table 3 Sixteen input characteristics for the FNN analysis

\begin{tabular}{|c|c|c|c|}
\hline \multicolumn{4}{|c|}{ Input number } \\
\hline 1 & Smoking habit & 9 & Hematocrit (\%) \\
\hline 2 & Blood urea nitrogen $(\mathrm{mg} / \mathrm{dl})$ & 10 & RBC (million cells/ $\mu \mathrm{L}$ ) \\
\hline 3 & Creatinine $(\mathrm{mg} / \mathrm{dl})$ & 11 & WBC (cells/ $\mu \mathrm{L})$ \\
\hline 4 & Uric Acid (mg/dl) & 12 & Urine urobilinogen (\%) \\
\hline 5 & $\gamma$-GTP (IU/L) & 13 & Urine protein (\%) \\
\hline 6 & Hemoglobin (g/dl) & 14 & Urine sugar (\%) \\
\hline 7 & GOT (IU/L) & 15 & Urinary occult blood (\%) \\
\hline 8 & GPT (IU/L) & 16 & Alcohol habit \\
\hline
\end{tabular}

an independent variable and the definition of "case subject" or "healthy control subject" as a dependent variable. Study estimates were adjusted for age, drinking habit, smoking habit and the components of MetS including BMI, systolic blood pressure, diastolic blood pressure, triglyceride, HDL-cholesterol and fasting plasma glucose. In replication study, we added exercise habit for adjustment. In addition, using correlation coefficient and correlation ratio, we tested the association between the selected characteristic and other clinical characteristics. A characteristic was considered statistically significant at a $P$ value of less than 0.05 . All statistical analyses were performed with $\mathrm{R}$ software (Version 2.13.1, http://www. r-project.org/).

\section{Results}

\section{Clinical characteristics}

The clinical characteristics before study start in the original study and in the replication study are listed in Tables 1 and 2, respectively. In both studies, the weight, BMI, systolic blood pressure, diastolic blood pressure, serum total cholesterol, serum triglyceride, and fasting plasma glucose were significantly higher in the case subjects than in the healthy control subjects, whereas serum HDL-cholesterol was significantly lower in the case subjects. In the replication study, the case subjects were significantly taller than the healthy control subjects.

\section{FNN analysis (original study)}

By means of the FNN analysis of health check-up data before study start from the original study (Table 4), we identified a combination of the $\gamma$-glutamyltranspeptidase $(\gamma$-GTP) level and the white blood cell (WBC) count as being indicative of MetS. The FNN analysis had a high accuracy of $77.4 \%$ compared with the baseline of $63.7 \%$ calculated by the null method that estimates all subjects to be case subjects or healthy control subjects. This accuracy in FNN analysis was similar to an accuracy of $75.8 \%$ in multiple linear regression and an accuracy of $75.8 \%$ in multiple logistic regression. This combination of parameters, which showed the best predictive accuracy, is illustrated as a fuzzy rule in Figure $2 \mathrm{~A}$. In this matrix, most case subjects were classified in the high $\gamma$-GTP level $(\geq 26.9 \mathrm{IU} / \mathrm{L})$ and high WBC count $\left(\geq 5.83 \times 10^{3}\right.$ cells $\left./ \mu \mathrm{L}\right)$ group, whereas most healthy control subjects were classified in the low $\gamma$-GTP level $(<26.9 \mathrm{IU} / \mathrm{L})$ and low WBC count $\left(<5.83 \times 10^{3}\right.$ cells $\left./ \mu \mathrm{L}\right)$ group. The numbers of case subjects and healthy control subjects are shown in the upper line of each cell of the matrix and the weights required to yield a case of MetS are shown in the lower line of each cell of the matrix. The matrix for the high $\gamma$-GTP level and high WBC count showed a high weight of 1.07 , which corresponds to a significant factor for a case of MetS. This trend was also shown by a scatter plot of $\gamma$-GTP level versus WBC count (Figure 3A).

\section{FNN analysis (replication study)}

The replication study confirmed the association between MetS development and a combination of a high $\gamma$-GTP level and a high WBC count. The FNN analysis showed a high accuracy of $67.1 \%$ compared with a baseline of $50.0 \%$. This accuracy was similar to an accuracy of $66.1 \%$ in multiple linear regression and an accuracy of $68.5 \%$ in multiple logistic regression (Table 4). In the fuzzy rule, most case subjects were classified as showing a combination of a high $\gamma$-GTP level $(\geq 30.2 \mathrm{IU} / \mathrm{L})$ and a high WBC count $\left(\geq 6.64 \times 10^{3}\right.$ cells $\left./ \mu \mathrm{L}\right)$, which corresponded to a high weighting of 1.08 (Figure 2B). This fuzzy rule was also visualized as a scatter plot (Figure 3B).

\section{Statistical verification of the $\gamma$-GTP level and WBC count as an indicator of MetS}

Table 5 shows the differences in the $\gamma$-GTP level and the WBC count between the case subjects and the healthy

Table 4 Inputs selected by FNN

\begin{tabular}{|c|c|c|c|c|c|c|c|c|c|}
\hline \multirow[t]{2}{*}{ Study } & \multirow{2}{*}{$\begin{array}{l}\text { Input } \\
\text { number }\end{array}$} & \multirow{2}{*}{$\begin{array}{l}\text { Baseline } \\
(\%)\end{array}$} & \multirow[t]{2}{*}{ FNN } & \multicolumn{2}{|c|}{ Accuracy (\%) } & \multicolumn{2}{|c|}{ number of subject } & \multicolumn{2}{|c|}{ Input characteristic } \\
\hline & & & & $\begin{array}{l}\text { multiple linear } \\
\text { regression }\end{array}$ & $\begin{array}{l}\text { multiple logistic } \\
\text { regression }\end{array}$ & Case & $\begin{array}{l}\text { Healthy } \\
\text { control }\end{array}$ & 1 input & 2 inputs \\
\hline \multirow[t]{2}{*}{ Original Study } & 1 input & 63.46 & 73.88 & 69.23 & 73.72 & 57 & 99 & Y-GTP (IU/L) & - \\
\hline & 2 inputs & 63.71 & 77.43 & 75.81 & 75.81 & 45 & 79 & y-GTP (IU/L) & WBC (cells/ $\mu \mathrm{L})$ \\
\hline \multirow[t]{2}{*}{ Replication Study } & 1 input & 50.00 & 64.96 & 64.18 & 66.44 & 2196 & 2196 & Y-GTP (IU/L) & - \\
\hline & 2 inputs & 50.00 & 67.14 & 66.10 & 68.53 & 2196 & 2196 & y-GTP (IU/L) & WBC (cells $/ \mu \mathrm{L})$ \\
\hline
\end{tabular}




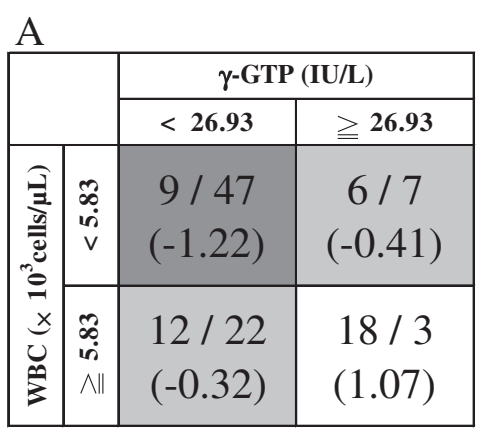

Case/Healthy control

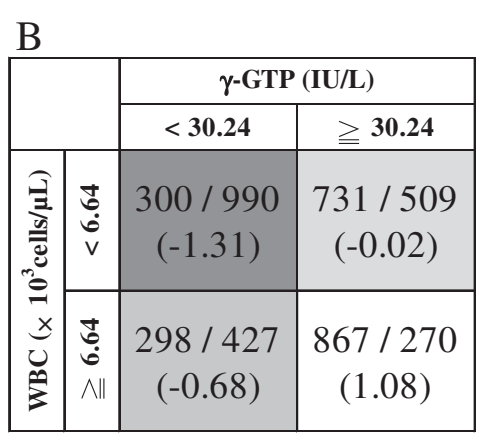

Case/Healthy control

Figure 2 Fuzzy rule. The fuzzy rule visualizes the risk combination identified by FNN analysis. The numbers of case subjects and healthy control subjects are shown in the upper line of each cell of the matrix, and the weights required to yield a case of MetS are shown in the lower line of each cell of the matrix. In both studies, most case subjects were classified as showing high levels of $y$-GTP and high WBC counts, giving a high weight of 1.07 or 1.08 , which means a significant factor for a case of MetS. (A): Original study. (B): Replication study.

control subjects. The difference between $\gamma$-GTP level and MetS was significant after adjusting for age, drinking habit, smoking habit and the components of MetS (original study: $P=0.014$, replication study: $P=1.71 \times 10^{-5}$, combined study: $\left.P=3.11 \times 10^{-6}\right)$. This significant difference remained significant after adjusting for exercising habit in replication study $\left(P=1.69 \times 10^{-5}\right)$. Although the difference between WBC and MetS was weak after adjusting for age, drinking habit, smoking habit and the components of MetS in replication study, the association remained significant in combined study (original study: $P=0.002$, replication study: $P=0.107$, combined study: $P=0.031)$. These results showed that the $\gamma$-GTP level and the WBC count, as selected by FNN analysis, together form a statistically reliable indicator.

To explain the difference between the $\gamma$-GTP levels in the original study (mean in healthy control subjects $=16.3 \mathrm{IU} / \mathrm{L}$ ) and those in the replication study ( mean in healthy control subjects $=27.3 \mathrm{IU} / \mathrm{L}$ ), we compared the clinical characteristics of the participants in the two studies. We found that age had a significant effect $\left(P<1.0 \times 10^{-99}\right)$, so we investigated the correlation coefficient between age and $\gamma$-GTP levels. A scatter plot of age versus $\gamma$-GTP levels showed that the difference in the mean $\gamma$-GTP level was due to age (Figure 4).

Finally, we calculated correlation ratio for the original study (Table 6). The $\gamma$-GTP level was significantly associated with habitual drinking of alcohol $\left(P=1.41 \times 10^{-2}\right)$, but not with habitual smoking $(P=0.406)$. On the other hand, the WBC count was significantly associated with habitual smoking $\left(P=1.18 \times 10^{-5}\right)$, but not with habitual drinking $(P=0.695)$. The same tendency was found in the replication study (Table 7).

\section{Discussion}

In our study, we used an FNN as a computational method to analyze complex characteristics. The FNN analysis is a powerful machine-learning method for detecting, with maximal accuracy, significant combinations of characteristics that are associated with a particular attribute. By using an FNN, we identified that a
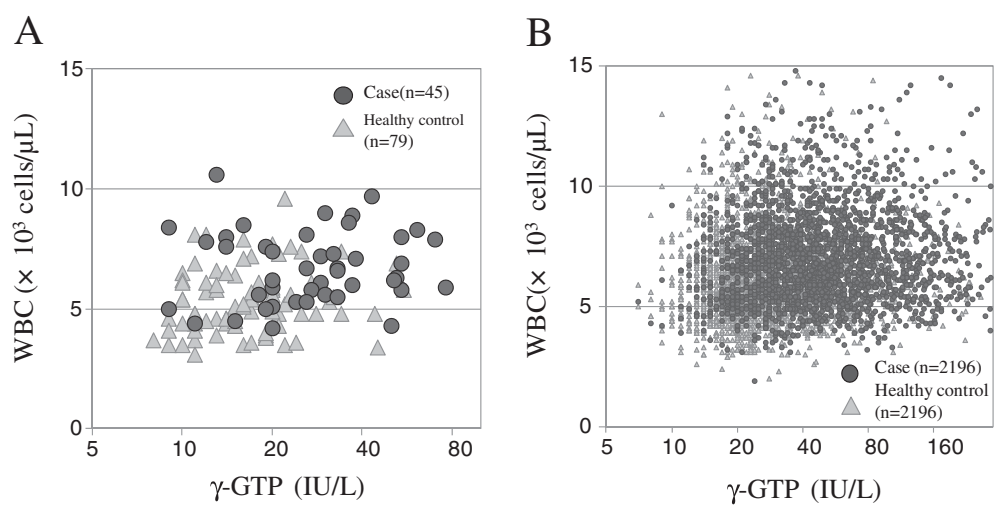

Figure 3 Scatter plots of $\boldsymbol{\gamma}$-GTP level versus WBC count. Scatter plots of $\gamma$-GTP level versus WBC count show that a combination of an elevated $y$-GTP level and an elevated WBC count is associated with MetS. (A): Original study. (B): Replication study. 
Table 5 Statistical analysis of characteristics selected by FNN

\begin{tabular}{|c|c|c|c|c|c|c|c|c|c|}
\hline \multirow[t]{2}{*}{ Study } & \multirow[t]{2}{*}{ Characteristic } & \multicolumn{2}{|c|}{ model 1} & \multicolumn{2}{|c|}{ model $2^{b}$} & \multicolumn{2}{|c|}{ model $3^{c}$} & \multicolumn{2}{|c|}{ model $4^{d}$} \\
\hline & & OR $(95 \% \mathrm{Cl})$ & $P$ value & OR $(95 \% \mathrm{Cl})$ & $P$ value & OR $(95 \% \mathrm{Cl})$ & $P$ value & OR $(95 \% \mathrm{Cl})$ & $P$ value \\
\hline \multirow[t]{2}{*}{$\begin{array}{l}\text { Original } \\
\text { Study }\end{array}$} & $\begin{array}{l}\text { Y-GTP } \\
\text { (doubling) }^{a}\end{array}$ & $\begin{array}{c}4.71 \\
(2.63-8.41)\end{array}$ & $1.69 \times 10^{-7}$ & $\begin{array}{c}5.98 \\
(3.12-11.5)\end{array}$ & $7.25 \times 10^{-8}$ & $\begin{array}{c}4.06 \\
(1.33-12.4)\end{array}$ & 0.014 & - & \\
\hline & $\begin{array}{l}\text { WBC } \\
\text { (1000 cells/ML) }\end{array}$ & $\begin{array}{c}1.83 \\
(1.39-2.41)\end{array}$ & $1.62 \times 10^{-5}$ & $\begin{array}{c}1.94 \\
(1.41-2.65)\end{array}$ & $3.86 \times 10^{-5}$ & $\begin{array}{c}2.69 \\
(1.44-5.02)\end{array}$ & 0.002 & & \\
\hline \multirow[t]{2}{*}{$\begin{array}{l}\text { Replication } \\
\text { Study }\end{array}$} & $\begin{array}{l}\gamma \text {-GTP } \\
\text { (doubling) }^{a}\end{array}$ & $\begin{array}{c}2.64 \\
(2.45-2.85)\end{array}$ & $<1.0 \times 10^{-99}$ & $\begin{array}{c}2.84 \\
(2.62-3.08)\end{array}$ & $<1.0 \times 10^{-99}$ & $\begin{array}{c}1.32 \\
(1.17-1.51)\end{array}$ & $1.71 \times 10^{-5}$ & $\begin{array}{c}1.33 \\
(1.17-1.51)\end{array}$ & $1.69 \times 10^{-5}$ \\
\hline & 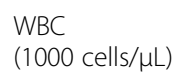 & $\begin{array}{c}1.31 \\
(1.26-1.35)\end{array}$ & $2.73 \times 10^{-51}$ & $\begin{array}{c}1.30 \\
(1.25-1.35)\end{array}$ & $5.06 \times 10^{-42}$ & $\begin{array}{c}1.05 \\
(0.99-1.12)\end{array}$ & 0.107 & $\begin{array}{c}1.06 \\
(0.99-1.12)\end{array}$ & 0.094 \\
\hline \multirow[t]{2}{*}{$\begin{array}{l}\text { Combined } \\
\text { Studye }\end{array}$} & $\begin{array}{l}y \text {-GTP } \\
(\text { doubling) }\end{array}$ & $\begin{array}{c}2.65 \\
(2.46-2.86)\end{array}$ & $<1.0 \times 10^{-99}$ & $\begin{array}{c}2.86 \\
(2.64-3.10)\end{array}$ & $<1.0 \times 10^{-99}$ & $\begin{array}{c}1.35 \\
(1.19-1.53)\end{array}$ & $3.11 \times 10^{-6}$ & - & \\
\hline & $\begin{array}{l}\text { WBC } \\
\text { (1000 cells/ } \mu \mathrm{L})\end{array}$ & $\begin{array}{c}1.32 \\
(1.27-1.36)\end{array}$ & $1.28 \times 10^{-55}$ & $\begin{array}{c}1.31 \\
(1.26-1.36)\end{array}$ & $1.62 \times 10^{-45}$ & $\begin{array}{c}1.07 \\
(1.01-1.14)\end{array}$ & 0.031 & & \\
\hline
\end{tabular}

Odds ratio (OR) with $95 \%$ confidence interval $(\mathrm{Cl})$ indicates the proportional change in risk associated with each increase by the amount indicated in parentheses. a geometric mean (2.5-97.5\%) was used because of skewed distriburions.

Differences in characteristics between case and healthy control subjects were evaluated by logistic regression analysis.

${ }^{b}$ Differences were evaluated by logistic regression analysis with adjustment for age, drinking habit and smoking habit.

'Differences were evaluated by logistic regression analysis with adjustment for age, drinking habit, smoking habit and the components of MetS.

${ }^{d}$ Differences were evaluated by logistic regression analysis with adjustment for age, drinking habit, smoking habit, the components of MetS and exercise habit.

en combined study, the difference of study was added in adjustment.

combination of the $\gamma$-GTP level and the WBC count is a characteristic that is associated with MetS. As shown in Table 4, the accuracy in FNN analysis was similar to the accuracy in multiple linear regression and the accuracy in multiple logistic regression. However, FNN analysis also has an ability to visualize the risk of the high $\gamma$-GTP level and high WBC count group easily using fuzzy rule as Figure 2. The FNN also lacked statistical significance, so we reexamined selected characteristics by means of statistical analysis with suitable adjustments. The statistical results confirmed that the $\gamma$-GTP level and the WBC count are significant factors in MetS, confirming that the FNN has good predictive powers and is suitable for use in practical applications.

We excluded the characteristics included in judgments of metabolic syndrome. We firstly conducted FNN analysis including the components of metabolic syndrome, selecting a combination of triglycerides and WBC. However, we thought these components directly affect the prevalence of MetS. We aimed to search latent risk factors using remaining 16 clinical and laboratory characteristics. We showed that an elevated $\gamma$-GTP level and an elevated WBC count are combinational risk factors for MetS. $\gamma$-GTP is a marker of fatty liver disease and $\gamma$-GTP levels have been found to be associated with the prevalence of MetS in previous East Asian studies [20-22]. An increase in levels of liver enzymes may be related to excess deposition of fat in the liver. The WBC count is a marker of systemic inflammation and it has also been found to be associated with the prevalence of MetS in a previous study [23]. The WBC count is controlled by cytokines, especially interleukin- 6 and interleukin-8 [24], and WBCs play a major role in inflammatory processes and in defending the body against
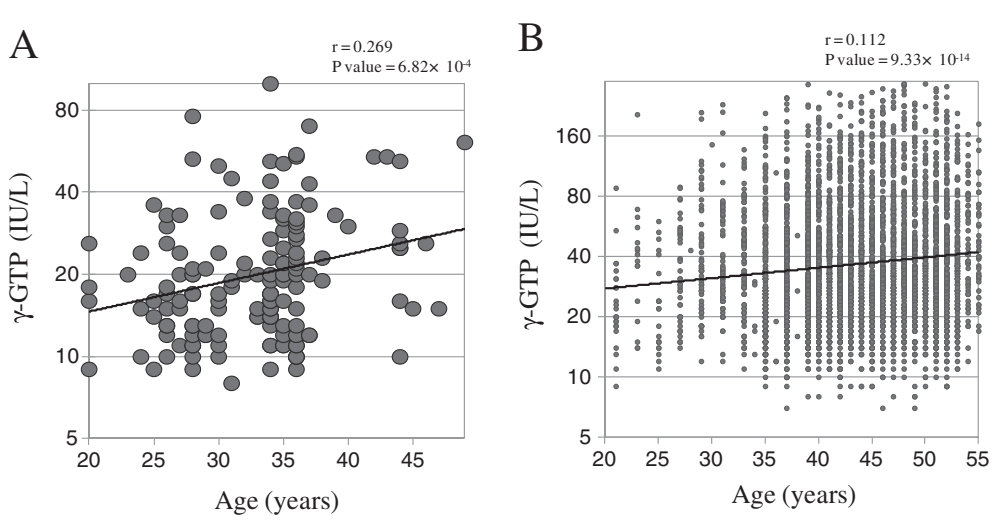

Figure 4 Scatter plots of age versus $\gamma$-GTP level. Scatter plots of age versus $\gamma$-GTP level show that the difference in the $\gamma$-GTP level between the original study and the replication study was due to the age of the subjects. (A): Original study. (B): Replication study. 
Table 6 Correlation ratios in original study

\begin{tabular}{lllrr}
\hline Characteristic $\mathbf{1}$ & Characteristic $\mathbf{2}$ & $\mathbf{n}$ & \multicolumn{1}{c}{$\mathbf{n}$} & $\boldsymbol{P}$ value \\
\hline Y-GTP (IU/L) & Alcohol habit & 155 & 0.197 & $1.41 \times 10^{-2}$ \\
Y-GTP (IU/L) & Smoking habit & 153 & 0.068 & 0.406 \\
WBC (cells/ $\mu \mathrm{L})$ & Alcohol habit & 137 & -0.034 & 0.695 \\
WBC (cells $/ \mu \mathrm{L})$ & Smoking habit & 135 & 0.369 & $1.08 \times 10^{-5}$ \\
\hline
\end{tabular}

infectious disorders. In addition, a previous study has shown that the mean WBC count increases with an increase in serum $\gamma$-GTP [25]; this implied that elevated $\gamma$-GTP levels might reflect subclinical inflammation. This result from our FNN method may show that this combination has a synergistic effect.

Our study also showed that habitual drinking is related to an elevated level of $\gamma$-GTP, in agreement with a previous study [26]. However, we also showed that there is no significant association between habitual drinking and MetS. Similarly, we showed that habitual smoking is linked to an increase in the WBC count. However, the association between habitual smoking and MetS was low significant. This tendency was the same that found in a previous study [27]. Although $\gamma$-GTP levels and WBC counts are generally included in blood tests performed during periodic health examinations, these characteristics have seldom been considered in risk assessment. Our result could be useful in a personalized riskprevention method, advising people with elevated $\gamma$-GTP level and an elevated WBC count to improve their diet and physical activity.

In this study, completely healthy people were used as controls. We also conducted logistic regression analysis between case subjects who developed MetS during the follow-up and normal control subjects who weren't MetS during the follow-up. In original study, including 77 case subjects and 597 normal control subjects, the significant association between $\gamma$-GTP and MetS wasn't observed $(P$ value $=0.213)$. On the other hand, the significant association between WBC and MetS was observed $\left(P\right.$ value $\left.=4.76 \times 10^{-4}\right)$. In replication study, including 2196 case subjects and 27246 normal control subjects, the significant association between $\gamma$-GTP and MetS was observed $\left(P\right.$ value $\left.=5.00 \times 10^{-21}\right)$. The significant association between WBC and MetS was also observed $\left(P\right.$ value $\left.=1.41 \times 10^{-26}\right)$. Although our study couldn't find significant association between $\gamma$-GTP and

Table 7 Correlation ratios in replication study

\begin{tabular}{|c|c|c|c|c|}
\hline Characteristic 1 & Characteristic 2 & $n$ & $\eta$ & $P$ value \\
\hline$\overline{\gamma-G T P(I U / L)}$ & Alcohol habit & 4389 & 0.232 & $<1.0 \times 10^{-99}$ \\
\hline$\gamma$-GTP (IU/L) & Smoking habit & 4390 & 0.068 & $7.01 \times 10^{-6}$ \\
\hline WBC (cells/ $\mu \mathrm{L}$ ) & Alcohol habit & 4389 & -0.074 & $9.74 \times 10^{-7}$ \\
\hline WBC (cells $/ \mu \mathrm{L})$ & Smoking habit & 4390 & 0.386 & $<1.0 \times 10^{-99}$ \\
\hline
\end{tabular}

MetS in original study partly because of small sample, we showed significant associations in replication study consisted of large subjects. This result suggests that both of the association between $\gamma$-GTP and MetS and the association between WBC and MetS may be derived from the difference between those who will develop the overt clinical picture of metabolic syndrome and those who will develop some of its components without fulfilling the criteria for its diagnosis.

Our present study has several limitations however. First, for clinical data before the follow-up, we used a modified definition of MetS involving the BMI instead of the waist circumference; however, several studies have shown that the BMI is an equally effective characteristic as the waist circumference and it has been adopted for analyses of the association between the adiponection gene and metabolic traits, including MetS [28]. Secondly, we analyzed data from male subjects exclusively. This was because only one woman showed an indication of MetS among 2061 Japanese company employees in our original study. Although the potential bias was minimized by adjusting for age, drinking habit, and smoking habit, our findings may have limited value in the case of women. Thirdly, we could not subdivide drinking habit and smoking habit quantitatively. As in a previous study [26], the strength of risk of MetS may be related to the drinking status or the smoking status.

\section{Conclusions}

We have shown that the combination of the $\gamma$-GTP level and the WBC count is the most significant risk factor associated with MetS. By using a statistical analysis adjusted by age, drinking habit, smoking habit and the components of MetS, we confirmed that the FNN analysis method is suitable for identifying combinations of factors associated with the risk of lifestyle diseases. Our results may be useful in providing a novel personalized diagnostic and therapeutic method, depending on the individual subject's $\gamma$-GTP level and WBC count.

\footnotetext{
Abbreviations

ADIPOR1: Adiponectin receptor 1; BMl: Body-mass index; CV: Cross-validation; FNN: Fuzzy neural network; $\gamma$-GTP: $\gamma$-Glutamyltranspeptidase; GOT: Glutamicoxyacetic transaminase; GPT: Glutamic-pyvuvic transaminase; HOMAIR: Homeostasis model assessment-insulin resistance; LDL: Low-density lipoprotein; HDL: High-density lipoprotein; MetS: Metabolic syndrome; RBC: Red blood cells; WBC: White blood cells.
}

\section{Competing interests}

The authors declare that they have no competing interests.

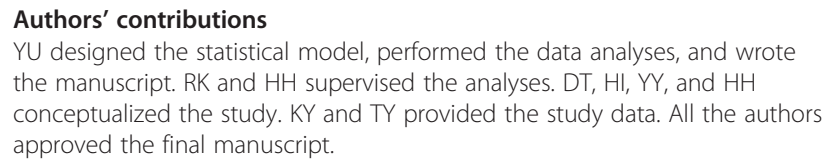




\section{Acknowledgements}

This study was partially supported by Special Coordination Funds for Promoting Science and Technology provided by the Japanese Ministry of Education, Culture, Sports, Science and Technology.

\section{Author details}

'School of Engineering, Nagoya University, Furo-cho, Chikusa-ku, Nagoya 464-8603, Japan. ${ }^{2}$ NGK Insulators, Ltd, Sudacho, Mizuho-ku, Nagoya 467-8530, Japan. ${ }^{3}$ Nagoya University School of Medicine, Tsurumaicho, Showa-ku, Nagoya 466-8550, Japan. ${ }^{4}$ NGK Health Insurance Society, Sudacho, Mizuho-ku, Nagoya 467-8530, Japan. ${ }^{5}$ Aoyama Clinic, Sakae 3-7-13, Naka-ku, Nagoya 460-0008, Japan. ${ }^{6} \mathrm{MEXT}$ Innovative Research Center for Preventative Medical Engineering, Furo-cho, Chikusa-ku, Nagoya 464-8601, Japan. ${ }^{7}$ Faculty of Pharmacy, Meijo University, Yagotoyama 150, Tenpaku-ku, Nagoya 468-8503, Japan.

Received: 26 December 2011 Accepted: 11 July 2012

Published: 1 August 2012

\section{References}

1. Robert HE, Scott MG, Paul ZZ: The metabolic syndrome. Lancet 2005, 365:1415-1428.

2. McCurry J: Japanese people warned to curb unhealthy lifestyles: health experts urge a return to dietary basics to prevent future health problems. Lancet 2004, 363:1126.

3. Panagiotakos DB, Pitsavos C, Skoumas J, Chrysohoou C, Toutouza M, Stefanadis Cl, Toutouzas PK: Importance of LDL/HDL cholesterol ratio as a predictor for coronary heart disease events in patients with heterozygous familial hypercholesterolaemia: a 15-year follow-up (1987-2002). Curr Med Res Opin 2003, 19:89-94.

4. Nakatochi M, Miyata S, Tanimura D, Izawa H, Asano H, Murase Y, Kato R, Ichihara S, Naruse K, Matsubara T, Honda H, Yokota M: The ratio of adiponectin to homeostasis model assessment of insulin resistance is a powerful index of each component of metabolic syndrome in an aged Japanese population: results from the KING study. Diabetes Res Clin Pract 2011, 92:e61-e65.

5. Ushida $Y$, Kato R, Tanimura D, Izawa H, Yasui K, Takase T, Yoshida Y, Kawase M, Yoshida T, Murohara T, Honda H: Determination of combinational genetic and environmental risk factors of lifestyle-related disease by using health check-up data obtained from long-term follow-up. Seibutsu Kogaku Kaishi 2010, 88:562-569.

6. Hirose H, Takayama T, Hozawa S, Hibi T, Saito I: Prediction of metabolic syndrome using artificial neural network system based on clinical data including insulin resistance index and serum adiponectin. Comput BiolMed 2011, 41:1051-1056.

7. Honda H, Kobayashi T: Fuzzy control of bioprocess. J Biosci Bioeng 2000 89:401-408.

8. Hibino S, Hanai T, Nagata E, Matsubara M, Fukagawa K, Shirataki T, Honda H, Kobayashi T: Fuzzy neural network model for assessment of Alzheimertype dementia. J Chem Eng Jpn 2001, 34:936-942.

9. Ando T, Suguro M, Hanai T, Kobayashi T, Honda H, Seto M: Fuzzy neural network applied to gene expression profiling for prognosis of diffuse large B-cell lymphoma. Jpn J Cancer Res 2002, 93:1207-1212.

10. Ando T, Suguro M, Kobayashi T, Seto M, Honda H: Multiple fuzzy neural network system for outcome prediction and classification of 220 lymphoma patients on the basis of molecular profiling. Cancer Sci 2003, 94:906-913.

11. Hanai T, Katayama A, Honda H, Kobayashi T: Automatic fuzzy modeling for Ginjo sake brewing process using fuzzy neural networks. J Chem Eng Jpn 1997, 30:94-100.

12. Tomida S, Hanai T, Honda H, Kobayashi T: Construction of COD simulation model for activated sludge process by recursive fuzzy neural network. J Chem Eng Japan 2001, 34:369-375.

13. Tominaga O, Ito F, Hanai T, Honda H, Kobayashi T: Sensory modeling of coffee with a fuzzy neural network. J Food Sci 2002, 67:363-368.

14. Kato $\mathrm{R}$, Nakano $\mathrm{H}$, Konishi $\mathrm{H}$, Kato $\mathrm{K}$, Koga $\mathrm{Y}$, Yamane $\mathrm{T}$, Kobayashi $T$, Honda $\mathrm{H}$ : Novel strategy for protein exploration: high-throughput screening assisted with fuzzy neural network. J Mol Biol 2005, 351:683-692.

15. Ushida $Y$, Kato R, Morimoto T, Honda H: Detection of physical environmental factors on comfortableness of housing. Trans Jpn SoC Kansei Eng 2009, 9:97-102.
16. Kaga C, Okochi M, Tomita Y, Kato R, Honda H: Computationally assisted screening and design of cell-interactive peptides by a cell-based assay using peptide arrays and a fuzzy neural network algorithm. Biotechniques 2008, 44:393-402.

17. Takeshita T, Okochi M, Kato R, Kaga C, Tomita Y, Nagaoka S, Honda H: Screening of peptides with a high affinity to bile acids using peptide arrays and a computational analysis. J Biosci Bioeng 2011, 112:92-97.

18. The Examination Committee of the Criteria for Metabolic Syndrome in Japan: Definition and criteria of the metabolic syndrome in Japan. Japan Intern Med 2005, 94:188-201.

19. Horikawa S, Furuhashi T, Uchikawa Y: On fuzzy modeling using fuzzy neural networks with the back-propagation algorithm. IEEE Trans Neural Netw 1992, 3:801-806.

20. Oda E, Kawai R, Watanabe K, Sukumaran V: Prevalence of metabolic syndrome increases with the increase in blood levels of gammaglutamyltransferase and alanine aminotransferase in Japanese men and women. Intern Med 2009, 48:1343-1350.

21. Ryu S, Chang Y, Woo HY, Yoo SH, Choi NK, Lee WY, Kim I, Song J: Longitudinal increase in gamma-glutamyltransferase within the reference interval predicts metabolic syndrome in middle-aged Korean men. Metabolism 2010, 59:683-689.

22. Xu Y, Bi YF, Xu M, Huang Y, Lu WY, Gu YF, Ning G, Li XY: Cross-sectional and longitudinal association of serum alanine aminotransaminase and gamma-glutamyltransferase with metabolic syndrome in middle-aged and elderly Chinese people. J Diabetes 2011, 3:38-47.

23. Lao XQ, Neil Thomas G, Jiang C, Zhang W, Adab P, Lam TH, Cheng KK: White blood cell count and the metabolic syndrome in older Chinese: the Guangzhou Biobank cohort study. Atherosclerosis 2008, 201:418-424.

24. van Oostrom AJ, Sijmonsma TP, Verseyden C, Jansen EH, de Koning EJ, Rabelink TJ, Castro Cabezas M: Postprandial recruitment of neutrophils may contribute to endothelial dysfunction. J Lipid Res 2003, 44:576-583.

25. Nakanishi N, Suzuki K, Tatara K: Serum y-glutamyltransferase and risk of metabolic syndrome and type 2 diabetes in middle-aged Japanese men. Diabetes Care 2004, 27:1427-1432

26. Haren MT, Li M, Petkov J, McDermott RA: Alcohol, metabolic risk and elevated serum gamma-glutamyl transferase (GGT) in indigenous Australians. BMC Publ Health 2010, 10:454

27. Ishizaka N, Ishizaka Y, Toda E, Nagai R, Yamakado M: Association between cigarette smoking, white blood cell count, and metabolic syndrome as defined by the Japanese criteria. Intern Med 2007, 46:1167-1170.

28. Tanimura D, Shibata R, Izawa H, Hirashiki A, Asano H, Murase $Y$, Miyata S, Nakatochi M, Ouchi N, Ichihara S, Yasui K, Yoshida T, Naruse K, Matsubara T, Yokota M: Relation of a common variant of the adiponectin gene to serum adiponectin concentration and metabolic traits in an aged Japanese population. Eur J Hum Genet 2011, 19:262-269.

doi:10.1186/1472-6947-12-80

Cite this article as: Ushida et al:: Combinational risk factors of metabolic syndrome identified by fuzzy neural network analysis of health-check data. BMC Medical Informatics and Decision Making 2012 12:80.

\section{Submit your next manuscript to BioMed Central and take full advantage of:}

- Convenient online submission

- Thorough peer review

- No space constraints or color figure charges

- Immediate publication on acceptance

- Inclusion in PubMed, CAS, Scopus and Google Scholar

- Research which is freely available for redistribution 